\title{
Drug Testing in the Prison System
}

\author{
Akinyemi Gabriel* \\ Faculty of Law, Criminology with Forensic Psychology, UK
}

*Corresponding author: Akinyemi Gabriel, Faculty of Law, Criminology with Forensic Psychology, London, UK.

\author{
Received Date: September 28, 2018 \\ Published Date: November 19, 2018
}

\begin{abstract}
The main objective of drug testing in the prison system is to screen inmates who take drugs, to recognize inmates who are junkies, to observe and prevent inmates in the prison system for further use and abuse of illicit substances. This essay reviews the most common tests carried out in the prison system to ascertain those who are using drugs. The emphasis is on the criminal justice system and how they identify junkies and in the prison system. When testing inmates in the prison system, there are some ethical and legal issues that should be considered, and these issues are different from those raised if the criminal justice system is testing other population. This essay starts by talking about the drug policy debate, criminological theories and concepts that determine drug testing in the prison system, further moves to the purpose, methods and issues (ethical and legal) of drug testing and wraps it up with conclusion and recommendations.
\end{abstract}

\section{Drug Policy Debate}

A legal philosopher, David AJ Richards [1] discussed that respect for human rights gave birth to the legalization of drugs, albeit under the supervisions of the physicians and William Buckley [2], the editor of conservative National Review, announced his support for drug legalization in 1985. Then in 1988, lots of journals and articles started to appear clamoring for decriminalization of drug use. The articles and journals suggested that by legalizing drug use the crisis of drug use in America's cities will be solved. Arnold Trebach [3] of the drug policy foundation wrote a symposium issue of the American behavioral scientist:"I am now convinced that our society would be safer and healthier if all of the illegal drugs were fully removed from the control of the criminal law tomorrow...I would be very worried about the possibility of future harm if that radical change took place, but less worried than I am about the reality of the present harm being inflicted every day by our current laws and polices".

Some school of thoughts wanted some specific drugs to be legalized while others wanted it for medical control. A famous writer, Peter Hamil [4] declares that: After watching the results of the plague since heroin first came to Brooklyn in the early fifties, after visiting the courtrooms and the morgues, after wandering New York's neighborhoods...and after consuming much of the literature on drugs, I've reluctantly come to a terrible conclusion: The only solution is the complete legalization of these drugs".
Peter Hamil [4] argues that cocaine should be sold in liquor stores while heroin should be supplied in neighborhood health stations and drug stores to "registered addicts". Peter Hamil [4] however asserted that there should be criminal sanctions for those who "created new junkies" by selling drugs to those who are not addicted. Richard Dennis (1990) called for legalization of cocaine but not of crack, the potent and cocaine derivative that had so profoundly affected ghetto life in the late 1980's.

\section{Criminological Theories and Concepts}

Theories always expound how laws are formulated, and how the criminal justice system operates as a whole. Criminological theories are helps in shaping the society; these theories are used to broaden our knowledge about how the criminal justice system operates and those involved in it. Most of these criminological theories are similar even though there are still some glaring differences among them.

Bennett T \& Holloway K [5] affirms the link between drugs and violent crime, stating that there is no way to divorce drug addiction from crime in the society. From a social policy view, there is a relationship between drug abuse and crime and this impact on both criminal justice and drug policy. Seddon [6] argues that;

"Variances in propounded conceptions of the correlation between drugs and crime underlie the polarized debate regarding 
every aspect of the criminal justice system from treatment, prevention, enforcement, drug legalization, sentencing policy and strategy development for local policing"

Therefore, there should be some assessment of criminological theories and concepts that will support the relationship between drug and crime in the society before any other social policy initiatives are implemented.

According to Seddon [6] "The nature of the addiction itself is a significant causal trigger, which arguably predisposes a user to finding the necessary monies through crime to "feed" their habit" Goldstein [7] propounded the "economic compulsive" criminological theory. This he used to explain the relationship between drugs and crime. Seddon [6] said that the criminological theory debate was addressed in the United Kingdom in the 1990s. Seddon [6] further supports Goldstein [7] criminological theory that there is a strong relationship between both non-recreational and recreational drug use and crime. He explained the three basic prototypes between drugs and crime: drug use leads to crime; crime leads to drug use; both crime and drug use are related to other factors.

In the western world, there is a surge in drug use among inmates in the prison contrasted with percentages of the general population. Ministero della Giustzia (2001) says; $27 \%$ of the Italian prison population were labeled as drug dependent. koller (1997) opines that $29 \%$ of Swiss prisoners were found to be regular users of Heroin or Cocaine in 1993, compared to use amongst the general population of equivalent poly-drugs at $0.5 \%$. Furthermore, Brochu and Guyon (2007) declare that between a third and half of prisoners in Canada and France were also estimated to be drug dependent.

The report of EMCDDA (2002) further states that percentage proportions are clearly variable between prisons and jurisdictions, and there is also a general consensus in studies across Europe indicating that prisoners have a much higher rate of drug use compared with figures for the general population Home office report [8] says that;

"The links between drug use and crime are clearly established. In fact, around three-quarters of crack and heroin users claim they commit crime to feed their habit. It is our priority to break this damaging claim."

Richard and Senon [9] further argues that some criminal take advantage of the loopholes in the criminal justice system by exaggerating drug use in order not to accept responsibility for their crime and thereby getting a slap on the wrist. (Light sentence). Criminologists have explained the correlation between drug use and crime but haven't been able to explain how the abuse of different types of drugs makes crime vary.

\section{Techniques, Investigation and Claims}

Drug testing programs have been used on those arrested, those on probations and paroles, juvenile detainees and convicted criminals. White house [10] national drug policy asserts that; "Drug test should be a part of every stage of the criminal justice process, at the time of arrest and throughout the period of probation or incarceration, because they are the most effective way of keeping offenders off drugs both in and out of detention"

\section{Purposes of Drug Testing in the Prison}

Drug testing is basically used to;

- $\quad$ Detect persons who have swallowed an illicit drug

- $\quad$ Identify drug addicts (junkies)

- $\quad$ To observe and dissuade drug use among inmates under the authority of criminal justice system

\section{Screening of Recent Drug Use}

The most common reason for using drug tests in the prison system is to determine whether a person has used a drug in the recent past. Sometimes people ask why drug test in prison is necessary when one can simply ask inmates about their drug use. According to O'malley, Mc Glothlin, and Ginzburg [11], drug testing is a technique social researcher have used to access the validity of self- report information about recent drug use. If the drug tests tallies with what the inmate says, there is confidence in the truthfulness of the inmates' interview responses. Bonito, Nurco and Shaffer [12] Harrell [13] also declare that inmates will most likely report about their drug use when confidential research interviews is applied because this will give the inmates assurance that their identity will be anonymous and won't result into negative consequences. When inmates are questioned within the criminal justice system, they are most likely to be dishonest about their drug use therefore such report may not be relied upon.

The criminal justice system has a database of self-reports from offenders and inmates so there may be lots of reporting errors there since most of the information there are from the inmates and offenders. Sometimes, it may not be advisable to rely on the criminal justice records about the drug use of offenders and inmates.

\section{Identification of Chronic Users}

The main objective of identifying chronic drug users within the prison system is because of a finding that suggested that offenders and inmates who often use illicit drugs mostly cocaine and heroin commit higher rates of crimes more and are prone to violent behavior more than offenders and inmates who aren't chronic users of illicit drugs. According to McGlothlin, Anglin and Wilson [14] many offenders and inmates reduce their crime rates when drug use is reduced voluntarily or during treatment. Therefore, the criminal justice system can now use drug testing in the prison to differentiate and separate chronic drug users who are likely to be active criminals from less active criminals.

Wish, Toborg \& Bellassai [15] also affirms that inmates who are classified as high risk could receive special conditions of release or supervision premeditated to reduce their association with drugs, while low-risk persons could receive less supervision. However, the major challenge that these type of drug testing approach will face is that no single drug test can measure levels of drug involvement. There may be "false positives" within the prison system when trying to identify chronic drug users; this simply implies that when testing a large number of people, group of individual who test positive will consist of large mixed collection of experimental users, occasional users, protracted users and persons who may not be drug users but may have been mistakenly identified as such. 
Furthermore, an infrequent drug user may also test positive for multiple drugs, given the heavy adulteration and mixing of substances that occurs in the uncontrolled illicit drug market. One can't rely on a single test even when it identifies two or more drugs in the blood stream of an inmate without differentiating each person's level of drug use. This type of method cannot be relied on.

\section{Monitoring and Dissuasion of Drug Use}

Random or fixed schedule of sequential drug test can identify a person's level of drug use. These testing is also used to make inmates comply with conditions of release and to deter use of drugs. Drug abuse treatment programs have been relying on drug tests for some years to monitor compliance with treatment. According to Magura et al. urinalysis testing is a requirement in Newyork city that dispense methadone to clients. In the prison system, urinalysis or urine monitoring is occasionally used for suspected drug users on parole or probation by the officers in charge. If a person relapsed to drug use, a period of re-incarceration will follow suit. According to McGlothlin, Anglin, \& Wilson [14]; Anglin (1978), these evaluations found that treatment with urine supervision reduced drug use and crime while persons remained in the program. Monitoring programs may also serve as a check or deterrence on persons not being tested from using drugs. Urine monitoring can also be applied as a primary rationale for random testing in the prisons. Urine or breath testing could be requested at the direction of the prison governor or the prison physician under specified condition. Testing can be conducted either for cause or as a random screening device for the entire inmates. Any positive urine tests can be interpreted as evidence of abuse and the inmate should be rehabilitated within the four walls of the prison.

\section{Drug-testing Methods}

To determine if a person has been using drugs, there are some indicators to watch out for. According to Gropper [16], three categories of indicators and related tests may be defined on the basis of the body systems involved and their temporal patterns, how soon they appear and how long they remain detectable.

Clinical behavioral indicators are behavioral and central nervous system effects that tend to appear rapidly after ingestion of drugs. They manifest through changes in speech patterns, brain waves, pupillary reaction and body coordination coupled with psychological orientation. Some of these effects may be measured by simple observation while others require sophisticated devices.

Metabolic indicators are related to the body's metabolism, storage and excretion of drugs. These include measures of bodily fluids such as blood, urine, saliva and breath while structural indicators can provide evidence of drug use long after the drug has been eliminated from other body systems and has ceased to have a psychoactive effect.

According to report of Bureau of Justice Assistance [17] the criminal justice system uses clinical behavioral and metabolic indicators. Examples of clinical behavioral tests are breathalyzer, which is usually used in drunken driving case, drug detection procedure which includes oral interview, a physiological examination, and a battery of behavioral tests.
For metabolic indicator, urinalysis is what they use primarily to detect drugs, and these include blood tests. Drugs are prone to be detected quickly in the blood, but their detection is limited by the short period they circulate in the blood provided the person does not take more drugs that will contaminate his blood. According to Hawks and Chiang (1986) the same analysis used in urine testing can be applied to saliva testing because obtaining saliva is less complex compared to other methods.

Structural indicators of drug use were developed recently by the criminal justice system. According to Harkey \& Henderson [18] structural indicators involves analysis of hair specimen by an experimental technique in which the drug is extracted from the hair and analyzed using radioimmunoassay tests. Gropper [19]; Wish Toborg \& Bellassai [15] also asserts that hair analysis has lots of advantages over metabolic tests.

\section{Legal and Ethical Issues Involved in Drug Testing}

\section{Ethical issue}

To get a urine specimen from an inmate in a prison can be a herculean task. The inmates especially the ones who are chronic drug users can go to any length to avoid been detected by urinalysis. Persons who have advance warning of the drug testing may substitute clear urine for their own through ingenious mechanical devices. They may also dilute their specimen with water or add some substance that will pollute the test so that drugs won't be detected in their urine. Some inmates may feel this is an intrusion on their privacy by the criminal justice system while others who are in the prison whose guilt or innocence has not yet been determined by the criminal justice system may see this as intrusive. Another ethical question is the provision of the urinalysis specimen. Should it be voluntary? If it is voluntary, should the inmate be informed about the rights he may give up if he provides the urinalysis specimen?

For those inmates in the prison system whose innocence and guilt hasn't been ascertained yet, the ethical questions to consider is should the inmate be told that by providing a urinalysis specimen, he might be giving the prosecutor information that could be used against him when defending himself? Should the inmate's lawyer(s) be consulted before the urinalysis test is carried out? How far should a positive test result follow an inmate? Should the inmate be labeled a drug user based on a single test result? The answers provided will depend on the stage the criminal justice system process the inmate is in. According to Toborg \& Bellassai [15]; ethical issues are greatest when testing a person at the pretrial stage before guilt has been determined. Furthermore, ethical issues like these must be debated and decided before a testing program is established.

\section{Legal Concerns}

Drug testing inside and outside of the criminal justice system has been examined by a growing body of case law. Adler [20] argues that;

"Federal and state courts that have recently considered mandatory drug testing requirements imposed by government authority have held them to be unreasonable and therefore 
unconstitutional if they were not based on a standard of individualized suspicion"

The legal issues that may arise include; is it right for the government to order random drug testing in the absence of reasons to suspect a person of using? The right of the criminal justice system to order random testing of inmates, those on probations and paroles and with those detained in police cells has yet to be determined. The current situation of different standards and procedures across the country should be replaced by acceptable scientific guidelines that will meet the needs of the criminal justice system.

\section{Conclusion and Recommendations}

Some research has looked into the correlation between drug tests results at arrest and pretrial misconduct. It hasn't yet been established how a positive test result relates to a person's likelihood of drug dependence. The percentage of inmates who are found to be using a certain drug hasn't been determined whether they are casual experimental users or chronic addicts. Strategies needs to be developed to estimate a person's risk of abusing drug and felonious conduct on the basis of drug tests result, criminal record and personal attributes. There should also be a way to determine a person who abuse two or more drugs and someone who tests positive for only one drug.

Furthermore, the criminal justice system will be able to identify drug users with the introduction of drug testing but little has been known about strategies on how to reduce drug use. The most effective type of treatment should also be determined. It's also penitent to note here that urine alone doesn't produce reduction in drug use and crime because urine monitoring alone can's deter other addicts from using drugs. Hair analysis also needs to be tested by many independent researchers and controlled comparisons should be made between self-reports of drug use, urinalysis and hair analysis.

Davis et al [21] believes that competence of testing laboratories varies greatly and high rate of false negative report appear to be the norm. Criminal justice system needs to develop uniform guidelines for drug testing; the development of small portable screening tests could also make drug testing much more practical for the criminal justice system [22].

Lastly, the major issue raised by bureaucrats faced with the decision whether to introduce drug testing into the criminal justice system is the lack of law enforcement and treatment resources to address drug problems in the large group of abusers identified. There is a critical need for cost-benefit analysis of the potential long-term savings to be achieved by identifying and treating criminal drug abusers so that policymakers can make rational decisions about drug testing.

\section{Acknowledgement}

None

\section{Conflict of Interest}

No conflict of Interest.

\section{References}

1. Richards DAJ (1981) Drug Use and the Rights of the Person: A Mora Argument for Decriminalization of Certain Forms of Drug Use. Symposium on Punishment: Critiques and Justifications. Rutgers Law Review 33: 607-86.

2. Buckley WF (1985) Does Reagan mean it? National Review 37:54

3. Trebach AS (1989) Tough Choices: The Practical Politics of Drug Policy Reform. American Behavioral Scientist 32: 249-58.

4. Hamil P (1988) Facing Up to Drugs: Is Legalization the Solution? 21-7

5. Bennett T, Holloway K (2005) Understanding Drugs, Alcohol and Crime. Berkshire Open University Press.

6. Seddon T (2000) Explaining the Drug-Crime Link: Theoretical Policy and Research Issues. Journal of Social Policy Cambridge University Press.

7. Goldstein P (1985) The Drugs/Violence Nexus: A Tripartite Conceptual Framework. Journal of Drug Issues 15 (4): 493-506.

8. Home Office (2006) Drug Related Crime: London: Home Office.

9. Richard D, Senon JL (1997) Delinquance et toxicomanie. A propos des liens entre comportement toxicomanieque et comportement delinquent. Toxibase Dossiers documentaires.

10. White House (1989) National Drug Control Strategy. Washington, Dc: US Government Printing Office.

11. O Malley P, WH McGlothlin, H Ginzburg (1977) Measurement content. In Conducting Follow-up Research on Drug Treatment Programs.

12. Bonito AJ, DN Nurco, JW Shaffer (1976) The veridicality of Addicts' Self Reports in Social Research. Int J Addict 11(5): 719-724.

13. Harrel AV (1985) Validation of Self-Report: The Research Record.

14. McGlothlin WH, MD Anglin, BD Wilson (1977) An Evaluation of the California Civil Addict Program. National Institute on Drug Abuse Research Monograph Series.

15. Wish ED, M Toborg, J Bellassai (1988) Identifying Drug Users and Monitoring them during Conditional Release. National Institute of Justice Briefing Paper. Washington, DC: US Department of Justice, National Institute of Justice.

16. Gropper BA (1987) Advancing the State of the Art in Drug Testing. Paper presented at the annual meeting of the American Society of Criminology.

17. Bureau of Justice Assistance (1989) Drug Recognition Program. Washington, DC: Bureau of Justice Assistance.

18. Harkey MR, GL Henderson (1988) Hair Analysis for Drugs of Abuse: A critical Review of the Technology. Final report submitted to the California Department of Alcohol and Drug Programs, Sacramento.

19. Gropper BA (1988) Drug Detection: Developing New Approach for Criminal Justice Questions.

20.Adler AR (1986) Testimony before the Subcommittee on Human Resources, Committee on Post Office and Civil Service. US House of Representatives.

21. Davis KH, RL Hawks, RV Blanke (1988) Assessment of Laboratory Quality in Urine Drug Testing: A Proficiency Testing Pilot Study. JAMA 260 (12): 1749-1754.

22. Anglin D (1988) The Efficacy of Civil Commitment in Treating Narcotic Addiction. In Compulsory Treatment of Drug Abuse: Research and Clinical Practice, edited by CG Leukefeld and FM Tims. National Institute on Drug Abuse Research Monograph no.86 Rockville, Md. U.S Department of Health and Human Services, National Institute on Drug Abuse. 